\title{
A moral dos senhores e dos escravos: um estudo antropológico segundo o pensamento de Nietzsche
}

\author{
The morals of masters and slaves: an anthropological study according to \\ Nietzsche's thought
}

\author{
CARLOS ALBERTO CÁCERES ${ }^{1}$
}

\begin{abstract}
Resumo: Nesse trabalho busco fazer um estudo dos valores morais segundo a interpretação do filosofo Nietzsche, onde começo a desenvolver um estudo a respeito das origens desses valores é onde entramos na antropologia para entender o quando esses valores influência um povo e a sua cultura. Partindo desse estudo irei fazer uma analise do conceito de bom do qual era utilizado pela classe aristocrática, onde esse conceito tinha como fim o valor de superioridade e bondade dos nobres, o oposto dos valores dos escravos, assim quando essa classe se estranhou e entrou em guerra, nobres lutando contra nobres, houve uma classe derrotada do qual Nietzsche denomina a classe sacerdotal, e essa classe derrotada cria os seus valores e se uni aos escravos, tornando assim a moral dos escravos, moral do qual Nietzsche fala que triunfou sobre a aristocracia, a moral dos escravos nega a realidade, o oposto dos nobres que eram a favor da realidade e da vida, os escravos estão além da vida, vivem em um ideal acético, é onde Nietzsche diz que inicia o ponto de declínio dos valores.

Palavras-chave: Nietzsche. Moral. Genealogia. Origem. Valores
\end{abstract}

\begin{abstract}
The aim of this work is a study of moral values according to the interpretation of philosopher Nietzsche, where a study about the origins of these values is developed. For that, we introduce the concept of anthropology in order to understand when these values influence a civilization and its culture. We also analyse the concept of good, which was used by aristocratic class. This concept had its purpose as the value of superiority and goodness of the nobles and the opposite of the values of the slaves, as well when this class was surprised war, nobles fought against nobles, there was a defeated class of which Nietzsche calls the priestly class, and that defeated class creates its values and unites itself with the slaves, thus making the moral of the slaves, a moral of which Nietzsche speaks that he triumphed over the aristocracy, slave morality denies reality, the opposite of nobles who were in favor of reality and life, slaves are beyond life, live in an acetic ideal, this is where Nietzsche says he begins the point of decline in values.
\end{abstract}

Keywords: Nietzsche. Moral. Genealogy. Origen. Value

\section{Introdução}

Nietzsche em sua obra Genealogia da Moral desenvolve uma crítica intensa aos valores morais que vêm desde Sócrates e outros pensadores e posteriormente a

\footnotetext{
${ }^{1}$ Possui Graduação em Filosofia pela Universidade Estadual do Norte do Paraná UENP, Centro de Ciências Humanas e da Educação (CCHE/CJ) campus Jacarezinho PR. Fez parte dos programas como bolsista, Programa institucional de bolsa de iniciação à docência PIBID, Programa Institucional de Bolsa de Iniciação Cientifica PICV, Programa Residência Pedagógica todos pela CAPES. Atualmente pesquisador nas áreas da Filosofia Antiga, Metafísica voltado para o estudo do Tempo e Antropologia. Fonte: http://lattes.cnpq.br/.E-mail: carlos_music82@hotmail.com
} 
partir de ideologias judaico-cristã ${ }^{2}$. Nietzsche é um filósofo da amoralidade; ele apresenta a sua suspeita sobre a questão dos valores na cultura, e parte desde o surgimento desses valores. Nietzsche entende que os valores não são universais e que eles mudam com o passar do tempo. Tais valores sempre estão ligados a uma noção de força, onde ele faz uma crítica a moral. "Enunciemo-la" - retrata ele, "esta nova exigência: necessitamos de uma crítica dos valores morais, o próprio valor dos valores deva ser colocado em questão". (NIETZSCHE, 2009, p. 12). Assim, partindo dessa obra de Nietzsche irei trabalhar a questão do valor moral e o quando é importante o estudo sobre valores morais, e o quanto ele influencia um povo e uma cultura, irei trabalhar apenas a primeira dissertação da obra Genealogia da Moral que o nosso autor deu o título de "bom e mau", "bom e ruim".

Nessa primeira dissertação, já vamos ver a importância do pensamento de Nietzsche e como ele desenvolve o seu pensamento na questão dos valores morais estabelecidos pela aristocracia, pelos sacerdotes e pelos escravos. Através das guerras, os aristocratas eram possuidores da sua moral; surge então a classe derrotada que são os sacerdotes; ora, esses ressentidos criam um novo valor, uma nova moral, eles criam um ideal acético, ideal esse que os sacerdotes passam para os escravos ensinando novos valores, onde os escravos irão ter uma nova crença, um novo ideal onde irão perder a sua cultura.

Podemos ver que não existe um valor único, uma única moral, e é isso que irei mostrar através do pensamento de Nietzsche a importância de se estudar os valores desde o seu surgimento até os dias de hoje.

\section{A moral}

Nietzsche quer nos fazer entender que os juízos de valores são de origem humana, é onde ele estuda a historia da moral nos homens para entender como o homem é responsável pela criação de tais valores, o homem em seu ambiente sendo capaz de produzir cultura e historia e assim sendo o único na espécie capaz de fazer isso, e que no período pré-histórico ${ }^{3}$ o homem já era capaz de produzir tal coisa, ou seja, a moral é algo exclusivo da natureza humana.

Podemos ver como o homem usou da moral criada por si para conquistar e manipular o outro no decorrer da história como o próprio Nietzsche diz:

O caráter tosco da sua genealogia da moral se evidencia já no início, quando se trata de investigar a origem do conceito e do juízo "bom". "Originalmente" - assim eles decretam - "as ações não egoístas

\footnotetext{
${ }^{2} \mathrm{O}$ povo judeu assim como os cristãos expõem uma doutrina da salvação, doutrina essa que tenta responder a todos os sofrimentos existenciais.

3 Pré-histórico: Nietzsche denomina por pré-histórico todo o trabalho da moralidade dos costumes, momento em que se buscava a fixação do costume em cumprir costumes. Deleuze coloca que "Cultura significa adestramento e seleção. Nietzsche chama o movimento da cultura de 'moralidade dos costumes". (Deleuze, 1976, p. 62)
} 


\section{CÁCERES, C.}

foram louvadas e consideradas boas por aqueles aos quais eram feitas, aqueles aos quais eram úteis; mais tarde foi esquecida essa origem do louvor, e as ações não egoístas, pelo simples fato de terem sido costumeiramente tidas como boas, foram também sentidas como boas - como se em si fossem algo bom". (NIETZSCHE, 2009, p. 16).

Ao longo do trabalho, veremos o modo de vida dos senhores e dos escravos; também iremos ver a mudança de valores e como esses valores são criados. Assim, podemos ver que a moral dos nobres tem uma conexão com a vida e a natureza e, por outro lado, a moral dos escravos, remete àqueles que negam a vida, surgindo assim um distanciamento do homem com a natureza.

\section{A origem dos valores, o pathos de distância}

Nesse capítulo assim como nos outros, irei fazer uma análise antropológica e também filosofia do pensamento de Nietzsche onde o objeto de estudo é a celebre obra Genealogia da Moral, onde trataremos do primeiro capitulo dessa magnifica obra.

Ao analisarmos o conceito de origem do bom, irei mostrar como o conceito é invertido ao decorrer da história. Assim irei fazer um estudo antropológico para que possamos entender a criação de um conceito. Para tanto, temos que levar em conta quem o criou, a classe dominante ou dominada, a cultura e em que época histórica se passou. Para começar, irei tratar do conceito e do juízo "bom" e de "ruim" ambos criados pela classe dos nobres, visando explicar o que é o pathos de distância um termo usado por Nietzsche nessa sua obra. Trata-se, para ele, de compreender como o homem através do controle da linguagem determina o valor. Nietzsche critica o conceito "bom", pois esse conceito era analisado na visão dos nobres, senhores do qual detinham o controle da linguagem. O próprio Nietzsche diz:

Para mim é claro, antes de tudo, que essa teoria busca e estabelece a fonte do conceito "bom" no lugar do errado: o juízo "bom" não provém daqueles aos quais se fez o "bem"! Foram os "bons" mesmo, isto é, os nobres, poderosos, superiores em posição e pensamento, que sentiram e estabeleceram a si e a seus atos como bons, ou seja, de primeira ordem, em oposição a tudo que era baixo, de pensamento baixo, e vulgar e plebeu. (NIETZSCHE, 2009, p. 16).

E mais adiante Nietzsche nota:

O pathos da nobreza e da distância, como já disse, o duradouro, dominante sentimento global e uma elevada estirpe senhorial, em sua relação como uma estirpe baixa, com um "sob" - eis a origem da oposição "bom" e "ruim". (NIETZSCHE, 2009, p. 17) 
O pathos da nobreza e da distância, segundo Nietzsche, pode ser entendido como uma espécie de interação entre os nobres e os escravos onde evidencia a diferença entre os tipos de comportamento. Aí se permite estabelecer uma comparação e criar valores; percebe se que o pathos de distância é onde se cria os valores ao modo da nobreza, que se diferencia dos escravos através de conflitos; então o pathos de distância é o espaço do qual o nobre se reconhece superior e cria os valores a partir do seu sentimento de superioridade. Conforme ilustra Silva e Reis:

Dessa forma afirma-se que a diferença é uma espécie de base criadora do pathos de distância, sendo que esta diferença precede a criação dos valores, pois a valoração ao modo dos senhores neste contexto, só é possibilitada através da compreensão e da afirmação desta diferença entre um tipo de moral com tendência aos nobres e um tipo de moral com tendências escravas. (SILVA E REIS, 2015, p. 4)

O pathos de distância tem como objetivo nos mostrar a diferença entre os homens, que segundo os nobres as semelhanças e as diferenças que irão determinar o valor de um sujeito, foi através do pathos de distância que os nobres tiveram a referência do que seria o "bom", automaticamente os nobres criam um termo que diferencia uns dos outros, ou seja, a oposição ao seu modo de ser, que é onde eles criam o conceito de "ruim", a criação de um valor que é oposta aos nobres, ou seja, aqueles que não têm os mesmo costumes, a mesma cultura, Nietzsche escreve: "Precisamente o oposto do que se sucede com o nobre, que primeiro e espontaneamente, de dentro de si, concebe a noção básica de "bom", e a partir dela cria a representação de "ruim" (NIETZSCHE, 2009 p. 28-29), podemos ver como um valor o de "bom" e "ruim" dependendo de quem o determina pode fazer a diferença.

O direito dos senhores de criar valores vai tão longe que podemos até dizer que eles podem fazer parte da origem da linguagem, pois o conceito "bom" nos escritos antigos privilegia os aristocratas que, por sua vez, o "bom" é determinado conforme às ações dadas pelos próprios senhores, classe que infunde a total diferença do que seria o antônimo de bom no conceito dos plebeus, dos escravos e das classes mais baixas, do qual veremos nos próximos tópicos.

Podemos ver que todo o esforço de Nietzsche parte de estudar rigorosamente a linguagem, pois a moral é algo inserido na cultura e que toma forma teórica através da linguagem. É a linguagem que exerce o papel fundamental tanto na elaboração de termos como bom, mal, ruim, como também exerce a função de transmitir essa moral, pois a elaboração de valores se realiza por meio da linguagem. Podemos ver como a linguagem é importante não só na moral, como também em todo 
pensamento filosófico, pois é através das palavras que se criam os signos ${ }^{4}$ onde se desenvolve no pensamento humano. A linguagem traz implicações para uma dupla valoração da moral, um valor dos senhores e outro dos escravos, para Nietzsche.

Na história, podemos ver como o conceito de uma palavra ou um termo é usado de forma que privilegia uma classe. Podemos ver nos livros de histórias que ao lermos a história das conquistas de Roma sobre os povos sempre assistimos que Roma conquistou os bárbaros, levando-nos a pensar que esses povos não constituíam um povo evoluído. Até nas produções cinematográficas são relatadas as conquistas romanas dessa forma. Por aí podemos ver como o conceito de povo "bom" é empregado por uma classe que domina os bárbaros, fazendo-os escravos cujo desfecho é o etnocídio. E, para deixar claro, como define Pierre Clastres: "O etnocídio é, portando, a destruição sistemática de modos de vida e de pensamento diferentes daqueles que conduzem a empresa da destruição" (CLASTRES, 1982, p. 53-54), ou seja, a destruição da cultura de um povo.

Podemos ver que a classe dominadora extermina e destrói a cultura de um povo, estabelecendo a sua cultura como dominante. Assim observamos como um conceito é modificado e empregado por quem o domina. Por isso, Nietzsche sempre questiona quem definiu esses valores, ou seja, quem é o homem que diz que a verdade é melhor do que a mentira, quem é o homem que diz que o útil é melhor que o inútil. Nietzsche formula essa questão lançando mão de uma forma simbólica porque, por trás dos valores pregados, existem pessoas movidas por interesses; por detrás de um valor existem o interesse de quem o avalia. Com isso, se eu sou mais forte o meu bem prevalece mais do que o do outro; ora, tal valor está ligado à noção de força, ou seja, o mais forte dita o que é bom ou ruim. Nesse caso, o nobre, conforme Nietzsche, cria o valor de "bom" a partir de si; o nobre ele se sente bem, superior quando comparado a outros. É o que atesta segundo Silva e Reis:

Esse sentimento de bem-estar é proporcionado porque o nobre é um tipo de homem forte, que tem possibilidade de realizar suas vontades na realidade, e desta forma, o mesmo pratica ações pela qual ele sabe que elevará o seu sentimento de potência e bem-esta (SILVA e REIS, 2015, p. 5).

Ao levarmos isso para o fator da história, vimos que todo animal que habita na natureza existe um mais forte e outro mais fraco. Assim, ao decorrer da história, os homens travam batalhas sempre dominando o mais fraco. Isso faz surgir duas "castas" na sociedade humana, conforme Nietzsche, a primeira casta dos superiores denominada de senhores (aristocratas) e, a segunda casta, a dos inferiores escravos.

\footnotetext{
${ }_{4}^{4}$ Por signo, entende-se pela criação de um elemento simbólico que represente e identifique, do qual distingue a nobreza.
} 
Quando isso acontece os seres que se autodenominam superiores passam a emitir juízos sobre a vida; pois bem, tais juízos passam a se impor sobre os subjugados, ou seja, o conceito de "bom", segundo Nietzsche, nasce na pré-história como o juízo do mais forte, o juízo do forte sobre os seus atos, ou seja, o forte age e mesmo diz que os seus atos são bons. Ele cria os valores e define o que é o bom assim como comenta Silva e Reis:

Em seu percurso de investigação genealógica, o autor apresenta a ideia que o conceito de bom surge como um juízo elaborado por aqueles homens denominados como nobres, poderosos, aqueles que eram "bons mesmo", (superiores frente a homens mais fracos e impotentes) que possuíam um maior privilégio estabelecidos a partir das relações de poder e sentindo superiores, tomaram a si mesmo como referência para valoração, criando assim o valor de bom (SILVA e REIS, 2015, p. 5).

Podemos dizer que os nobres eram os dominantes e o que não forem considerados 'bons' serão chamados de o resto. Os senhores são definidores de valores a partir de seus atos, da sua natureza e da sua ação. Eles subjugam o bom, o atributo bom pertence a eles, pois eles são os conquistadores e não abrem mão do direito de nomear e do direito de como as coisas são. Assim, se formos ver, no decorrer da história e em tempos atuais, os seres humanos têm um prazer pela violência, a espécie humana tem instintos, e os senhores podem expressar os seus extintos porque são os fortes. Para estes, não há limites; portanto, eles põem para fora a vontade de poder. Até nos dias atuais, mesmo não sendo senhores e detentores do poder, muitos acabam fazendo algum uso da violência, mas os povos conquistados não podem expor a sua força porque os povos são subjugados pelos senhores e são proibidos de expor a sua força e os seus instintos. Isso se vê claramente em guerras pelo mundo, quando o povo dominado perde o seu direito de praticamente tudo. Nietzsche, a propósito, observa:

Os juízos de valor cavalheiresco-aristocrático têm como pressuposto uma constituição física poderosa, uma saúde florescente, rica, até mesmo transbordante, juntamente com aquilo que serve à sua conservação: guerra, aventura, caça, dança torneios e tudo o que envolve uma atividade robusta, livre, contente. (NIETZSCHE, 2009, p. 22).

Vimos que o homem aristocrático ele é robusto; ele goza de boa saúde e disposição com uma grande força física onde obtém sucesso em suas ações, como na guerra, na caça, possuidores de uma virilidade, como Silva e Reis analisa:

E como este tipo de homem dispunha de dotes físicos que lhe permitiam sobressair sobre os demais, pode dizer que fora desenvolvido um sentimento de pertencimento, onde a identidade desse homem estava ligada ao conflito, a disputa, a torneios e até 
mesmo a dança, meio pelo qual o homem se expressa fisicamente toda sua liberdade. (SILVA e REIS, 2015, p. 13).

Vemos que esse conceito de "bom" surge de acordo com aquele que o criou que são os homens denominados como nobres, poderosos; aqueles que eram realmente bons, seres superiores aos mais fracos e impotentes, onde eram possuidores de privilégios estabelecidos a partir das relações de poder, tomando para si mesmos a referência do valor de bom. Segundo Nietzsche, o que ocorre? O nobre toma, para si próprio, a referência para criar um juízo de bom porque o nobre vê, em si mesmo, esse modelo de homem bom e superior aos outros homens. Como Marton esclarece: "a maneira nobre de avaliar ressalta o sentimento de plenitude excesso da própria força [...] - sabe-se criador de valores" (MARTON, 200o, p. 80), o nobre não precisa se comparar com outro para se valorizar: ele é o modelo de homem perfeito, uma vez que a classe inferior só serve para os nobres se vangloriarem ainda mais a sua posição de ser superior. Silva e Reis anotam:

A criação deste juízo de bom, partindo de uma ação dele mesmo, pressupõe enquanto critério, uma ligação entre o sentir-se bom com a valoração de ser bom, tendo em vista que este sentir-se bom está ligado a um sentimento de superioridade que parte de uma diferenciação com outros tipos de costumes. (SILVA e REIS, 2015, p. 5).

O nobre se sente bem em criar o valor de bom, pois parte de sua própria ação e estilo de vida. Em razão disso, por se mostrar superior quando são comparados aos fracos, inferiores e comuns, esses não possuem a capacidade de crias valores e bemestar assim como os nobres o fazem. O nobre é um ser forte e usa as suas vontades para criar na realidade, ele "pratica ações pela qual ele sabe que elevará o seu sentimento de potência e bem-estar". (SILVA E REIS, 2015, p. 5). Enfim, a nobreza desenvolveu, para si, o conceito" bom", tornando os espiritualmente bem nascidos, privilegiados. Graças a isso, o criar esse conceito vem o outro, o de "ruim" no sentido de ser inferior, plebeu e baixo.

\section{A interioridade do homem, transformando o conceito de "bom" em "bem"}

Em um determinado momento, as castas guerreiras, impelidas pela vontade de poder que cada uma dessas castas tinha, entraram em confronto entre si, porque a essência do homem é a vontade de poder. Afinal, o homem não se preocupa com a sua conservação e sim com o domínio do outro; tais castas, depois de subjugar os escravos, começam a lutar entre si para ver quem são os mais superiores entre elas Sobre esse ponto de vista, vê-se o quanto o homem deseja o poder; não contente de ter escravos, ele começa a lutar entre si, e o que acontece, é que quando luta entre si 
surgem os vencedores dessas castas. Surgem, então, os perdedores das castas, os derrotados. Esses, ocupando o poder de quem os dominou, tiveram os seus instintos negados; eles não podem mais serem cruéis, estão à mercê de quem os dominou, estão proibidos de expressar os seus instintos. Então, a saída que esses perdedores encontraram foi internalizar esses instintos, ou seja, a única coisa que eles puderam fazer foi voltar esses instintos contra si mesmos. Era a única coisa que puderam fazer. Assim surge a interioridade do homem, um mundo dentro de si. Isso porque, segundo Nietzsche, o homem, por ser inibido em natureza, nasceu para fazer guerra. Um exemplo disso seria o homem que vive reprimido a sua vida toda e, em algum momento, explode. É o caso também de pessoas que entram em escolas, cinemas atirando, matando. Ao que parece, isso pode bem estar relacionado com algo retraído na infância dentro de si. Tais criminosos deixam dentro de si esses desejos, esses instintos internalizados. Como os pais que inibem esses instintos dentro de seus filhos, esses acabam internalizando tais sentimentos voltando-se inclusive contra si mesmos. Disso surge, na opinião de Nietzsche, outra casta, a casta dos derrotados, ou seja, o surgimento da casta sacerdotal. Nietzsche diz:

Os sacerdotes são, como sabemos, os mais terríveis inimigos - por quê? Porque são os mais impotentes. Na sua impotência, o ódio toma proporções monstruosas e sinistras, torna-se a coisa mais espiritual e venenosa. Na historia universal, os grandes odiadores sempre foram sacerdotes, também os mais ricos de espíritos comparado ao espirito da vingança sacerdotal, todo espirito restante empalidece. (NIETZSCHE, 2009, p. 23).

O sacerdote é aquele que interioriza os seus instintos, os sacerdotes são os monstros da moral, não podem agir, são hostis à guerra pelo fato de serem perdedores da guerra. Um exemplo são os pacifistas. Eles pedem paz e reclamam da violência porque não tem o poder de violentar, para entrar na guerra. Essa casta impossibilitada de se vingar irá propor a anulação do mundo da vida e dos sentidos. Ela passa a avaliar o mundo da vida a partir da derrota que ela teve aí. Ela passa a querer um mundo sem lutas e sem guerras, sem dor, "uma raça de tais homens do ressentimento resultará necessariamente mais inteligente que qualquer raça nobre, e venerará a inteligência numa medida muito maior". (NIETZSCHE, 2009, p. 27)

O que a casta sacerdotal propõe é transferir o valor da vida para fora da vida, transferir para um nada. Ora, isso é, segundo o que denomina Nietzsche, o ideal acético. A casta sacerdotal diz que temos que ter um ideal; como criadora da moral ela cria tudo em nome de Deus e tudo que você fará é em nome de Deus. O sacerdote diz que temos que abrir mão de nossos sentidos em nome de Deus. Você deve ser um ser pacifico em nome de Deus. Assim, o sacerdote cria o seu modo de vida a sua moral, diferente dos aristocratas que amam o mundo e a vida por reconhecer na vida o valor da vida e de sua felicidade. O "bom", para o aristocrata, está na vida. Já o “bom”, para o sacerdote, esta no além da vida, segundo Silva e Reis: 
Ao passo que a moral sacerdotal se expande, situa-se neste movimento aquilo que Nietzsche chama de declínio dos valores aristocráticos, pelo qual o sacerdote com precisão e fineza inverte a lógica e os valores aristocráticos. Para Nietzsche, dado este movimento inicia-se o projeto de golpe à realidade onde o homem começa a se tornar de um tipo decadente. (SILVA E REIS, 2015, p 13)

Os sacerdotes fazem a inversão do conceito "bom" para o conceito o de "bem". Vemos, aqui, para Nietzsche, a criação de um valor e, por mais que passe despercebido muitas vezes, esses valores são importantes para a história da sociedade. Há tempo, os nobres ditam regras: o "bom", para a aristocracia, é um atributo; já o "bem" se torna substantivo e o bem é o que está fora da vida. Eles passam então a pregar que a vida boa é a vida servil, ou seja, a vida como servo. $O$ ato de servir será recompensado além da vida, ou seja, o valor dos valores muda, segundo Silva e Reis:

Os valores empreendidos pelo sacerdote, como podemos perceber se cria de forma antagônica aos valores cavalheirescos, sendo que o ponto de criação desses valores se dá justamente nas forças do ressentimento, um pertinente ódio como sintoma da impotência desse sacerdote que se volta com toda sua reatividade contra o aristocrata que disfruta do poder e soberania. (SILVA E REIS, 2015, p. 13).

Esta é a decadência dos valores, um ideal acético: a servidão se torna algo comum e aceitável, se torna bem.

\section{O valor dos escravos}

Para entendermos melhor sobre a mudança de valor, empregaremos mais um exemplo. O cauteloso era, para a classe aristocrática, o medroso, o covarde aquele que foge da guerra, lembrando que existiam as duas castas, os dominantes e os derrotados. Esses são os sacerdotes. Não conseguindo superar os guerreiros aristocráticos, eles se unem aos escravos, ou seja, não conseguindo lutar com os guerreiros, a casta sacerdotal se une aos escravos, oferecendo, para os escravos, um remédio para o seu sofrimento promovendo o ideal acético, como rejeição da vida.

Podemos ver como a casta sacerdotal se aproveitou do sofrimento dos escravos; para esses, uma ilusão de conforto mostrando para o escravo um valor. $\mathrm{O}$ valor sacerdotal, segundo as suas regras e conceitos, espelha na história a mudança de um valor que interfere na cultura de um povo. Pois, um povo oprimido pelos seus senhores não pode fazer o que quer e quando pode é julgado pelas suas ações; ações 
essas que são valores criados pela casta sacerdotal onde decidem o que é moral, segundo Silva e Reis:

A moral da negação, esse "não" criador de valores se origina do ódio contra o homem potente. Ao passo que a moral sacerdotal se expande, situa-se neste movimento aquilo que Nietzsche chama de declínio dos valores aristocráticos, pelo qual o sacerdote com precisão e fineza inverte a lógica e os valores aristocráticos. (SILVA e REIS, 2015, p. 13).

Para Nietzsche, o homem começa a se tornar decadente fazendo os escravos acreditar que a vida é injusta em si, sendo que, na verdade, a vida é injusta para os sacerdotes, pois os sacerdotes são os derrotados. Através das colonizações, alguns conquistadores, querendo levar como se fosse uma espécie de paraíso para o povo conquistado, ilustra bem, como nos jesuítas 5 , essa lógica. Lógica essa aplicada nos povos indígenas ao que, com a sua moral, impuseram aos índios uma nova crença, um novo ideal acético. Esse ideal converte os costumes de um povo fazendo esse acreditar que há um ideal, um paraíso; que o sofrimento em vida é plausível. Fazendo isso, os escravos passam a negar a vida, acreditando que o sofrimento é algo merecedor, isto é, algo recompensador que os levará ao paraíso, como descreve Silva e Reis:

Para Nietzsche, esta inversão de valores é tida como um "golpe à moral aristocrata", sendo justamente este o momento em que a humanidade começa a assumir uma moral que tem como princípio e essência o ressentimento, nutrindo no homem um ódio contra a vida, e induzindo-o a fazer da moral um narcótico e veneno nocivo à vida. (SILVA e REIS, 2015, p. 10).

Segundo Nietzsche, houve uma disputa entre a cultura da moral de escravos contra uma cultura cavalheiresca, onde a disputa era o direito a afirmação e a imposição de seus valores ou avaliações. É preciso lembrar que ambos os tipos de moral descendem de uma mesma classe, a classe dominadora onde se separaram. Devido a essa separação, se instala uma guerra ideológica, e através desse conflito, se estabelecem os ideais escravos, conforme Silva e Reis:

A coletividade se sobrepôs o individualismo, a igualdade se colocou acima da afirmação das diferenças e do poder, a fraqueza se impôs sobre a potência, a abstenção sob o desejo, o medo sob a coragem, o "não" sob o "sim", a humildade sob o orgulho, o transcendente sob a terra, o ressentimento sob o bem estar, e por final, o sofrimento sob a alegria. (SILVA E REIS, 2015, p. 15).

\footnotetext{
${ }^{5}$ Os religiosos da Companhia de Jesus foram os primeiros missionários no Brasil que adotaram a prática de aldear ou reunir os índios com o objetivo de torná-los cristãos, sendo responsáveis pela criação das primeiras aldeias ou aldeamentos nas proximidades da cidade de Salvador, no século XVI. (SANTOS, 2013, p.o1)
} 
Um exemplo do qual podemos citar são os cristãos ressentidos que sufocaram a crença dos gregos, assim como a dos romanos, segundo Nietzsche: 'Pois os romanos eram os fortes e nobres, como jamais existiram mais fortes e nobre, e nem foram sonhados sequer: cada vestígio, cada inscrição deles encanta, se apenas se percebe o que escreve aquilo." (NIETZSCHE, 2009, p. 40). Nietzsche mostra que a cultura romana é a maior representação da classe aristocrática, onde a sua cultura e os seus costumes serviram como referência de moral, e o povo do ressentimento sufocou Roma. Os cristãos dos quais, ilustra Nietzsche, constituem o povo sacerdotal do ressentimento, venceram Roma:

\footnotetext{
"Mas que quer ainda você com ideais mais nobres"! Sujeitemo-nos aos fatos: o povo venceu - ou "os escravos", ou "a plebe", ou "rebanho" ou como quiser chama-lo - se isto aconteceu graças aos judeus, muito bem! Jamais um povo teve a missão maior na historia universal. (NIETZSCHE, 2009, p. 25).
}

Podemos ver o quando um povo através da história muda o conceito moral. Aos olhos de Nietzsche, não há valores absolutos. Esses últimos foram criados historicamente a partir de expectativas de avaliação, como, por exemplo, o que é o poder? Ora, para Nietzsche, tais noções não são categorias universais, bem e mal são valores temporais. Ou seja, os gregos tiveram o seu bem e o seu mal, os egípcios tiveram seu bem e seu mal assim como os cristãos. Como podemos medir a noção de força, para Nietzsche, a história é um jogo de forças, investigar a história é investigar a interpretação de mundo. Um exemplo disso é o que era bom para os gregos se tornou mal para os cristãos, assim podemos ver na história como os valores morais eles mudam conforme o tempo, o que é bom hoje se torna mal amanhã.

\section{Conclusão}

Assim, portanto, ao decorrer desse trabalho, podemos ver que Nietzsche faz um estudo dos valores através da linguagem onde o homem cria os valores, e ele cria o valor de bom baseado na sua visão de mundo. Os homens que constituem a classe aristocrática são os criadores desses valores. Nietzsche então usa o terno pathos de distância que implica que os nobres observam os escravos e interagem com eles estabelecendo uma diferença. Os nobres criam um valor, e é através dos conflitos que a classe aristocrática que se sente superior cria o valor de bom; tudo isso através do seu sentimento de superioridade, onde os nobres são os bons e atribuem para os escravos o valor de ruim.

Podemos ver que esses valores de bom e ruim dependendo de quem os aplicam pode mudar completamente o sentido de cada valor; por isso, que o estudo da linguagem é muito importante para entendermos esses conceitos. Em função disso, podemos recorrer a vários livros que contam histórias de guerras e nos 
perguntar se tais ocorrências se deram dessa forma mesmo? É que a maioria dos contos são contados pelos conquistadores e não pelos conquistados, havendo sempre um interesse de fundo.

Daí decorre uma noção de força, onde o mais forte dita o que é certo ao mais fraco. Quando essa classe entra em conflito com outra da mesma casta? Surgem os derrotados do qual Nietzsche denomina a classe sacerdotal, essa classe ressentida com a derrota começa a negar a vida e assim criam um ideal acético, algo além da vida. Com isso, os sacerdotes derrotados se unem aos escravos e infundem esse ideal acético para eles mudando completamente o sentido do valor de bom para bem. $\mathrm{O}$ bem é o que está fora da vida; isto é totalmente o oposto dos nobres onde o bom está na vida.

Portanto, vimos como um conceito pode mudar um povo criando vários valores morais no decorrer da história. Segundo o pensamento de Nietzsche, os valores mudam, estão ligados à noção de tempo, podemos nós mesmos ver que, nos últimos anos, o que era errado se torna certo, o que era bom se torna mal. Assim, portanto, os valores modificam e quem estiver no poder sempre irá ditá-los.

\section{Referências}

ABBAGNANO, N. Dicionário de Filosofia. 5. ed. São Paulo: Martins Fontes, 2007.

CLASTRES, P. “Do genocídio”. In: Arqueologia da violência. São Paulo: Brasiliense, 1982.

MARTON, S. Nietzsche: das forças cósmicas aos valores humanos. 2. ed. São Paulo: Editora UFMG, 2000.

NIETZSCHE, F. W. Genealogia da moral: uma polêmica, tradução, nota e posfácio de Paulo Cesar de Souza. São Paulo: Cia. Das Letras, 2009.

SANTOS, F. L. XXVII Simpósio Nacional de História - ANPUH - Natal, RN - 2013.

SILVA, T, F; REIS, E. P. Revista de Iniciação Científica - UNIFEG, Guaxupé - № 15 - 2015.

Submissão: 11. 02. 2021 / Aceite: 20. 08. 2021 